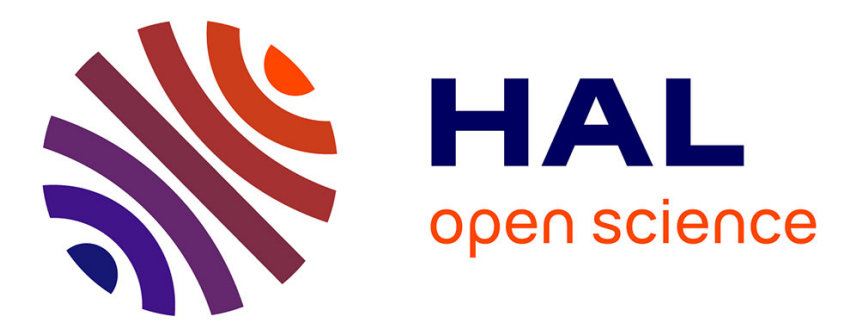

\title{
CDW instability in the 2:1 organic conductor (FA)2PF6
}

\author{
V. Ilakovac, S. Ravy, Jean Pouget, W. Riess, W. Brütting, M. Schwoerer
}

\section{To cite this version:}

V. Ilakovac, S. Ravy, Jean Pouget, W. Riess, W. Brütting, et al.. CDW instability in the 2:1 organic conductor (FA)2PF6. Journal de Physique IV Proceedings, 1993, 03 (C2), pp.C2-137-C2-140. 10.1051/jp4:1993227 . jpa-00251310

\section{HAL Id: jpa-00251310 https://hal.science/jpa-00251310}

Submitted on 1 Jan 1993

HAL is a multi-disciplinary open access archive for the deposit and dissemination of scientific research documents, whether they are published or not. The documents may come from teaching and research institutions in France or abroad, or from public or private research centers.
L'archive ouverte pluridisciplinaire HAL, est destinée au dépôt et à la diffusion de documents scientifiques de niveau recherche, publiés ou non, émanant des établissements d'enseignement et de recherche français ou étrangers, des laboratoires publics ou privés. 


\title{
CDW instability in the $2: 1$ organic conductor $(F A)_{2} \mathrm{PF}_{6}$
}

\author{
V. ILAKOVAC ${ }^{*},(1)$, S. RAVY*, J.P. POUGET*, W. RIESS ${ }^{* *}$, W. BRÜTTING ${ }^{* *}$ and \\ M. SCHWOERER ${ }^{* *}$ \\ * Laboratoire de Physique des Solides, URA CNRS 02, Université Paris-Sud, 91405 Orsay, France \\ ${ }^{* *}$ Phys. Inst. and BIMF, Universität Bayreuth, 8580 Bayreuth, Germany
}

\begin{abstract}
We present an X-ray diffuse scattering study of the fluoranthene radical cation salt $(\mathrm{FA})_{2} \mathrm{PF}_{6}$, where $\mathrm{FA}$ is the fluoranthene molecule, $\mathrm{C}_{16} \mathrm{H}_{10}$. Below room temperature this salt undergoes two successive structural phase transitions. The upper one, at $T_{\mathfrak{c}} \approx 200 \mathrm{~K}$, breaks the face center Bravais lattice symmetry. The lower one, of the Peierls type, corresponds to the $3 \mathrm{D}$ ordering of quasi-1D $2 \mathrm{k}_{\mathrm{F}}$ charge density waves $(C D W)$ at $T_{P}=180 \mathrm{~K}$, temperature below which collective transport phenomena are observed. We compare this material to the Bechgaard salts (TMTS(T)F) 2 X, of very similar stack structure but where a Peierls CDW ground state is not stabilized.
\end{abstract}

\section{Introduction}

Fluoranthene radical cation salts (FA) ${ }_{2} \mathrm{X}$, belong to a larger familly of arene salts $(\mathrm{Ar})_{2}{ }^{+} \mathrm{X}^{-}$, where $\mathrm{Ar}$ is an aromatic molecule and $\mathrm{X}$ is a monovalent anion like $\mathrm{PF}_{6}^{-}$. (FA) ${ }_{2} \mathrm{PF}_{6}$ is composed of slightly dimerized donor stacks of fluoranthene molecules piled in a zig-zag manner along the a direction [1] and whose structure strongly resembles to that of Bechgaard salts (TMTS(T)F $)_{2} \mathrm{X}$. Columns of anions $\mathrm{X}$ separate molecular stacks in the $\mathbf{b}$ and $\mathbf{c}$ directions. Stoichiometry $2: 1$ and full charge transfer to the anion $X$ lead to an average charge of 0.5 hole per FA and thus to $2 \mathrm{k}_{\mathrm{F}}=0.75 \mathrm{a}^{\prime *}$ or $0.5 \mathrm{a}^{*}$ depending whether the average molecular periodicity $a^{\prime}=\left(d_{1}+d_{2}\right) / 2$ or the true crystallographic periodicity $\left(a=2 a^{\prime}\right)$ is considered.

Electrical [2] and polarized reflectance [3] measurements prove that (FA) ${ }_{2} \mathrm{PF}_{6}$ is a very anisotropic 1D metal. Transport $[2,4]$ and magnetic [5] measurements show the existence of a metal-insulator phase transition at $T_{P} \approx 180 \mathrm{~K}$. Below this temperature collective transport phenomena are observed and interpreted as due to the sliding of CDW [4]. The main purpose of this paper is to present structural evidences of such a CDW transition and to clarify its relationship with the $\mathrm{A} 2 / \mathrm{m} \rightarrow \mathrm{P} 2{ }_{1} / \mathrm{c}$ structural transition previously reported by Enkelmann et al. [1].

\section{Experimental results} Bayreuth.

We studied two crystals coming from different preparations and grown at the University of

The first crystal was studied by the fixed film - fixed crystal method in order to have a general survey of the structural properties of $(\mathrm{FA})_{2} \mathrm{PF}_{6}$. One observes (fig. 1) :

- quasi $1 \mathrm{D}$ fluctuations giving rise to $2 \mathrm{k}_{\mathrm{F}}=0.5 \mathrm{a}$ * diffuse lines at room temperature (RT) ( $)$ 
- on the diffuse lines broad superstructure satellite reflections at the reduced wave vector $\mathbf{q}_{\mathrm{P}}=$ $(0.5,0,0)$ below $\mathrm{T}_{\mathbf{P}}=(179 \pm 1) \mathrm{K}(-)$

- new sharp reflections at $\mathbf{q}_{\mathrm{A}}=(0,1,1)$, which break the face center symmetry of the RT structure below $\mathrm{T}_{\mathrm{c}}=(201 \pm 1) \mathrm{K}(\mathbf{N})$.

$2 \mathrm{k}_{\mathrm{F}}$ quasi-1D fluctuations are observed from 300 to $30 \mathrm{~K}$ (the lowest temperature reached was 15K). Fig. 2 shows the temperature dependence of $\mathrm{T} / \mathrm{I}\left(2 \mathrm{k}_{\mathrm{F}}\right)$, where $\mathrm{I}\left(2 \mathrm{k}_{\mathrm{F}}\right)$ is the $2 \mathrm{k}_{\mathrm{F}}$ peak intensity. This quantity, proportional to the inverse CDW susceptibility, $\chi_{\rho}{ }^{-1}$, decreases linearly with $\mathrm{T}$. However, in this first sample $\chi_{\rho}{ }^{-1}$ does not vanish at $T_{P}$ in agreement with the observation of only a CDW short range order below $\mathbf{T}_{\mathbf{P}}$. (The Scherrer formulae applied to the half width at half maximum (HWHM) of the $\mathbf{q}_{\mathbf{P}}$ reflection gives a domain length $L \approx 45 \AA$ ).

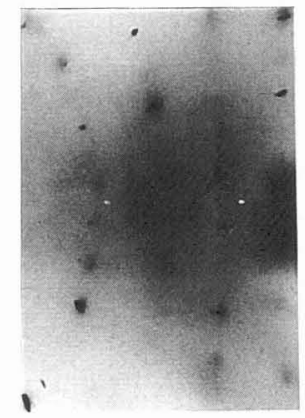

1a

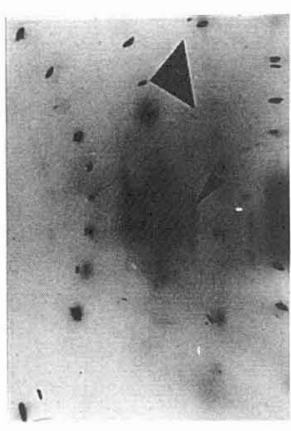

$1 \mathrm{~b}$

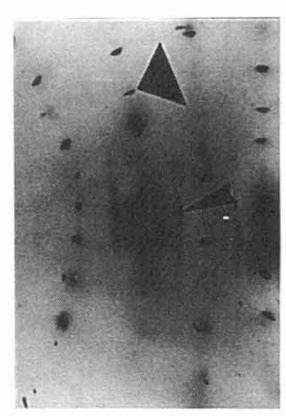

$1 \mathrm{c}$

Fig. 1. X-ray patterns of $(\mathrm{FA})_{2} \mathrm{PF}_{6}$ at $300 \mathrm{~K}$ (a), $190 \mathrm{~K}$ (b) and $175 \mathrm{~K}$ (c). The chain axis a is horizontal.

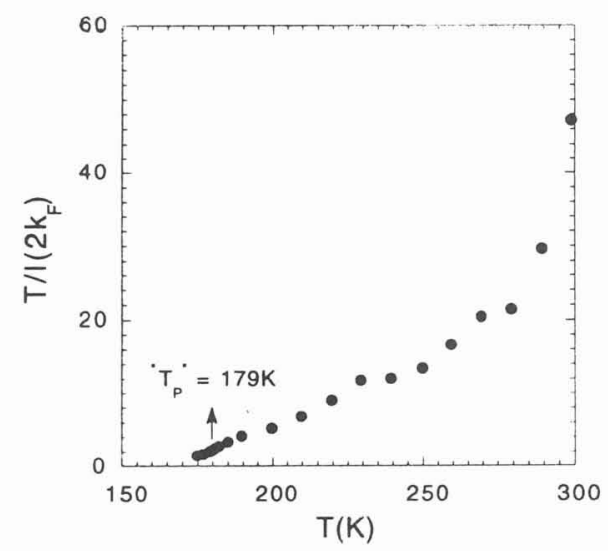

Fig. 2. Temperature dependence $\chi_{\rho}{ }^{-1}-\mathrm{T} / \mathrm{I}\left(2 \mathrm{k}_{\mathrm{F}}\right)$.

An accurate study of the two structural transitions was performed by a counter method on the second crystal. Figs. 3 and 4 show respectively the temperature dependence of the intensity of the $q_{P}$ and $\mathbf{q}_{\mathrm{A}}$ superlattice reflections, $\mathrm{I}\left(\mathrm{q}_{\mathrm{P}}\right)$ and $\mathrm{I}\left(\mathrm{q}_{\mathrm{A}}\right)$ respectively, as well as their $\mathrm{HWHM}$; at $\mathrm{T}=30 \mathrm{~K}: \mathrm{I}\left(\mathrm{q}_{\mathrm{A}}\right) \approx$ $\mathrm{I}(\mathrm{Bragg}) \approx 100 \mathrm{I}\left(\mathbf{q}_{\mathrm{P}}\right)$. Note that the width of the $\mathbf{q}_{\mathrm{P}}$ reflection amounts to that of the main Bragg reflections (i.e. the experimental resolution) which means that the sample has achieved a CDW long range 
order. Surprisingly, the $\mathbf{q}_{\mathrm{A}}$ reflections seem to have a width slightly larger than the experimental resolution. $\mathbf{I}\left(\mathbf{q}_{\mathbf{P}}\right)$ increases sharply below $\mathbf{T}_{\mathbf{P}}$ without a detectable hysteresis. $\mathbf{I}\left(\mathbf{q}_{\mathrm{A}}\right)$ increases linearly below $\mathrm{T}_{\mathrm{c}}$ but does not saturate at low temperature. The second crystal has slightly lower critical temperatures $\left[\mathrm{T}_{\mathrm{C}}=(194 \pm 1) \mathrm{K}, \mathrm{T}_{\mathrm{P}}=(176.7 \pm 0.3) \mathrm{K}\right]$ than the first one.

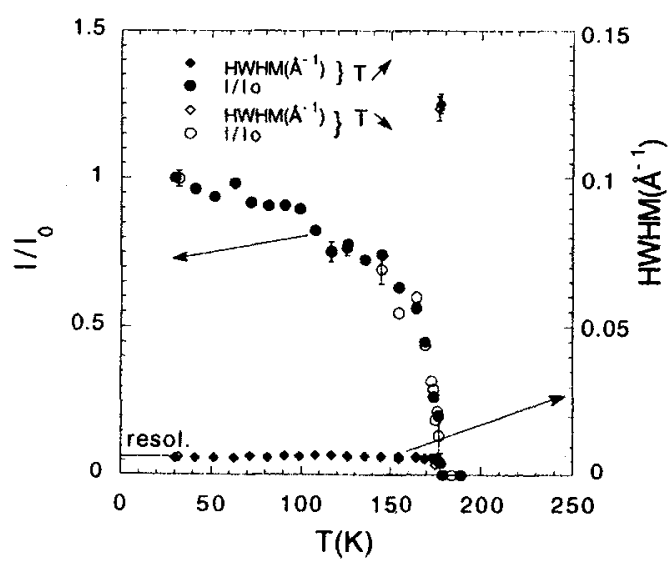

Fig. 3. Temperature dependence of the normalized integrated intensity and HWHM of the $q_{\mathrm{P}}$ reflection upon cooling and heating.

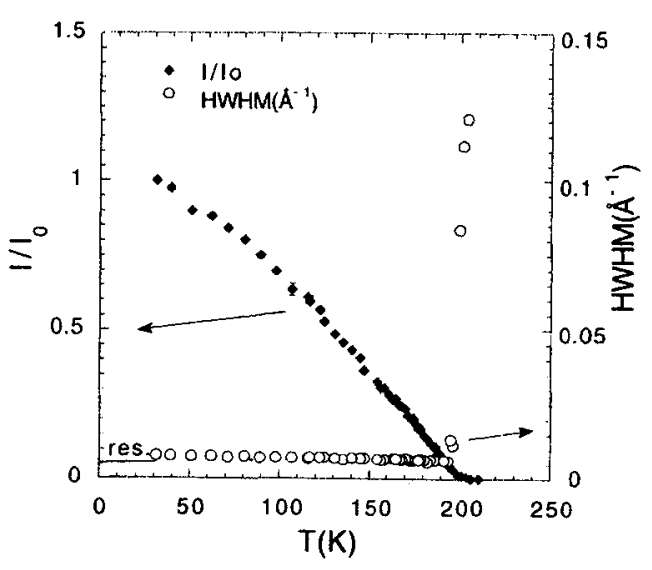

Fig. 4. Temperature dependence of the normalized integrated intensity and $H W H M$ of the $\mathbf{q}_{\mathrm{A}}$ reflection.

\section{Discussion}

$(\mathrm{FA})_{2} \mathrm{PF}_{6}$ undergoes two structural transitions which are apparently decoupled because the linear dependences of $\chi_{\rho}{ }^{-1}$ (fig. 2) and of $I\left(q_{A}\right)$ (fig. 4) are not modified at $T_{c}$ and $T_{P}$ respectively. The upper transition corresponds to the $\mathrm{A} 2 / \mathrm{m} \rightarrow \mathrm{P} 2{ }_{1} / \mathrm{c}$ structural change previously ascribed to an interstack staggered rotation of the FA molecules (fig. 5b) [1]. The lower one is a Peierls transition. It is announced by an important regime of $2 \mathrm{k}_{\mathrm{F}}$ quasi-1D fluctuations causing the opening of a pseudogap in the density of state which affects the thermal dependence of the conductivity [2] and magnetic susceptibility [5] above $T_{\mathrm{P}}$. The linear decrease of $\chi_{\rho}{ }^{-1}\left(2 \mathrm{k}_{\mathrm{F}}\right) \approx \mathrm{T}-\mathrm{T}_{\mathrm{P}}$ recalls that measured in the blue bronze [6] where the Peierls instability is driven by an important electron-phonon coupling. The interchain zero wave vector components of $q_{P}$ imply that the CDWs are in-phase along the $2^{\text {nd }}$ neighbouring stacks in $b$ and $c$ directions. In principle a structural refinement is necessary in order to determine the phase shift $\varphi$ between the $1^{\text {st }}$ neighbouring CDWs (fig. 5c) (a phase $\varphi=\pi$ is expected for equal Coulomb interactions between them). Finally, our investigation shows that the spatial extent of the $\mathrm{CDW}$ order in $(\mathrm{FA})_{2} \mathrm{PF}_{6}$ is very sensitive to the crystal quality (i.e. to chemical damage of the FA molecule).

Besides fluoranthene salts, a $2 \mathrm{k}_{\mathrm{F}} \mathrm{CDW}$ instability is also observed in $2: 1$ substituted perylene radical cation salts [7], but not in the Bechgaard salts. Table 1 compares more quantitatively (FA) ${ }_{2} \mathrm{PF}_{6}$ with the Bechgaard salts (TMTSF) $)_{2} \mathrm{PF}_{6}$ and (TMTTF $)_{2} \mathrm{PF}_{6}$ which have the same charge transfer and stack structure. The electron-electron interactions (leading to a spin susceptibility enhancement proportional to $t_{\|} \chi_{\text {spin }}$ ) increase from FA to TMTSF then to TMTTF salts while the ground state evolves from $2 \mathrm{k}_{\mathrm{F}}$ CDW to spin density wave (SDW) then to spin-Peierls (SP), respectively. Only in (TMTTF) ${ }_{2} \mathrm{PF}_{6}$ a true $4 \mathrm{k}_{\mathrm{F}}$ charge localization is observed. Table 1 shows that the degree of dimerization $\delta$ of the stacks does not follow the strength of Coulomb interactions, probably because $\delta$ is mainly determined by the interactions between $\sigma$ electrons on the donors and anions and not by the $4 \mathrm{k}_{\mathrm{F}}$ response 
of the $\pi$ electron clouds. The efficient screening of Coulomb interactions in the FA salts can be simply understood by the strong polarizability of the Ar molecules composed of a large number of rings.

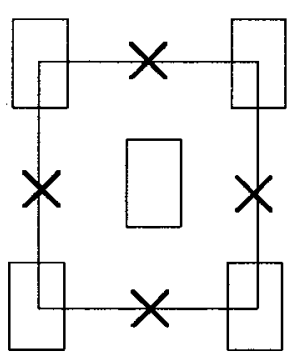

$5 \mathrm{a}$

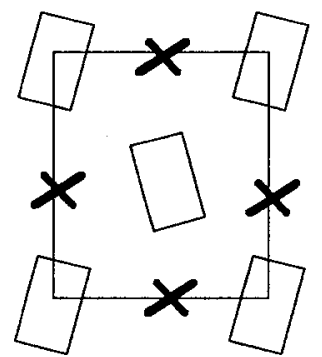

$5 b$
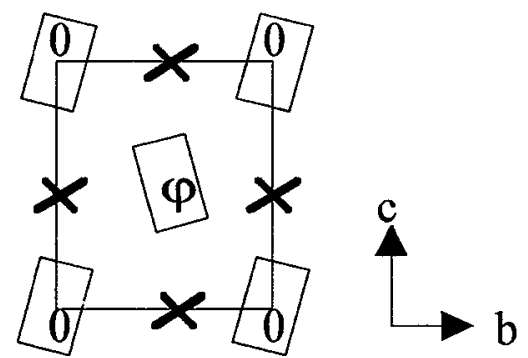

$5 c$

Fig. 5. Shematic representation of the projection along a direction of the structure of the $(F A)_{2} P F_{6}$ at $R T$ (a), between $T_{C}$ and $T_{P}(b)$ and below $T_{P}(c) . \varphi$ is the phase shift between $1^{\text {st }}$ neighbouring CDWs. The FA stacks are represented by open rectangles and the $\mathrm{PF}_{6}{ }^{-}$anions by crosses.

Table 1. Comparison between some physical properties of $(\mathrm{FA})_{2} \mathrm{PF}_{6}$ and of the Bechgaard salts $(\mathrm{TMTSF})_{2} \mathrm{PF}_{6}$ and $(\mathrm{TMTTF})_{2} \mathrm{PF}_{6}$.

\begin{tabular}{|c|c|c|c|c|c|c|c|c|c|}
\hline & $\begin{array}{l}\text { donor } \\
\text { molecule }\end{array}$ & $\begin{array}{c}\mathrm{RT} \\
\text { structure }\end{array}$ & $\delta^{\mathrm{RT}}=\frac{d_{2}-d_{1}}{d_{2}+d_{1}}$ & $\begin{array}{l}\sigma^{\mathrm{RT}} \| \\
(\Omega \mathrm{cm})^{-1}\end{array}$ & $\frac{\sigma_{I I}}{\sigma_{\perp}}$ & $\begin{array}{l}t_{1} \|^{o p t} \\
(e v)\end{array}$ & $\begin{array}{r}\chi^{\mathrm{RT}_{\text {spin }}} \\
(\mathrm{emu} / \mathrm{mol})\end{array}$ & $\begin{array}{l}4 \mathrm{k}_{\mathrm{F}} \text { charge } \\
\text { localisation }\end{array}$ & $\begin{array}{l}\text { ground } \\
\text { state }\end{array}$ \\
\hline $\mathrm{FA}_{2} \mathrm{PF}_{6}$ & & $\mathrm{~A} 2 / \mathrm{m}$ & $7.6 \times 10^{-3}$ & $10^{2}-10^{3}$ & $\sim 10^{4}$ & 0.35 & $1 \times 10^{-4}$ & NO & \begin{tabular}{|l|}
$\mathrm{CDW}$ \\
$(180 \mathrm{~K})$
\end{tabular} \\
\hline $\mathrm{TMTSF}_{2} \mathrm{PF}_{6}$ & & $\mathrm{P} \overline{1}$ & $4 \times 10^{-3}$ & 540 & $\begin{array}{l}\sigma_{\mathrm{a}} / \sigma_{\mathrm{b}^{\prime}}-10^{2} \\
\sigma_{\mathrm{a}^{\prime}} / \sigma_{\mathrm{c}}^{\prime} \sim 10^{4}\end{array}$ & 0.25 & $2.5 \times 10^{-4}$ & No & $\begin{array}{l}\text { SDW } \\
(12 K) \\
\end{array}$ \\
\hline $\mathrm{TMTTF}_{2} \mathrm{PF}_{6}$ & & Pī & $14 \times 10^{-3}$ & 40 & $?$ & 0.20 & $6 \times 10^{-4}$ & $\begin{array}{l}\text { YES } \\
\mathrm{T} \rho \approx 230 \mathrm{~K}\end{array}$ & $\begin{array}{l}\text { SP } \\
(15 \mathrm{~K})\end{array}$ \\
\hline
\end{tabular}

\section{Conclusion}

Below room temperature $(\mathrm{FA})_{2} \mathrm{PF}_{6}$ undergoes two close but independent structural transitions. The upper one coresponds to that previously reported in ref. [1]. The lower one is a commensurate CDW Peierls transition which provides the structural proof of the collective transport phenomena observed below $180 \mathrm{~K}$ [4]. However, it is interesting to remark that the treshold field measured in $(\mathrm{FA})_{2} \mathrm{PF}_{6}(0.1-$ $1 \mathrm{~V} / \mathrm{cm}$ [4]) is not so different from that observed in $-3 / 4$ and $-1 / 4$ filled band metals such as the blue bronzes $(-50 \mathrm{mV} / \mathrm{cm})[8]$ and $\mathrm{TaS}_{3}(200-300 \mathrm{mV} / \mathrm{cm})[6]$ whose $\mathrm{CDW}$ are incommensurate. This means either that $(\mathrm{FA})_{2} \mathrm{PF}_{6}$ could be considered as a $3 / 4$ filled band metal (i.e. $2 \mathrm{k}_{\mathrm{F}}=0.75 \mathrm{a}^{\prime *}$ ) where the pinning effects due to commensurability are weak, or that the observed nonlinear conductivity is due to slight deviations from the ideal 2:1-stoichiometry, as pointed out elsewhere [9].

[1] V.ENKELMANN, B.S.MORRA, Ch.KRÖNKE, G.WEGNER, Chemical Physics 6(1982)303

[2] W.BRÜTTING, W.RIESS and M.SCHWOERER, Ann.Physik 1(1992)409

[3] Th.SCHIMMEL, B.KOCH, H.P.GESERICH and M.SCHWOERER, Synth.Met. 33(1989)311

[4] W.RIESS, W.SCHMID, J.GMEINER and M.SCHWOERER, Synth.Met. 41-43(1991)2261

[5] U.KÖBLER, J.GMEINER and E.DORMAN, J.Magn.Magn.Mat. 69(1987)189

[6] CHARGE DENSITY WAVES IN SOLIDS, Eds. L.P.GO'RKOV and G.GRÜNER (North Holland, 1989.)

[7] P.PENVEN, D.JEROME, S.RAVY, P.A.ALBOUY and P.BATAIL, Synth.Met. 27(1988)B405

[8] LOW DIM. ELECT. PROP. OF Mo BRONZES AND OXIDES , Ed. C.SCHLENKER (Kluwer Acad. Publ., 1989.)

[9] W.RIESS, W.BRÜTTING, M.SCHWOERER, Synth.Met. 55-57(1993)2664 